\title{
Guest Editorial: Special Issue on "The 24th Electromagnetic Induction Workshop, Helsingør, Denmark"
}

\author{
Maxim Smirnov ${ }^{1} \cdot \mathrm{Kiyoshi}_{\mathrm{Baba}}{ }^{2}$
}

Published online: 7 December 2019

(c) Springer Nature B.V. 2019

Division VI of the International Association of Geomagnetism and Aeronomy (IAGA) on "Electromagnetic Induction in the Earth and Planetary Bodies" (https://www.emiw.org/) has long played an active role in the field of geophysics. Since 2015, the electromagnetic (EM) community has been accorded the status of a division within IAGA, which is one of the eight associations of the International Union of Geodesy and Geophysics (IUGG). The EM Induction Workshop (EMIW), one of the most important activities of the Division, has been held biennially since its inception in 1972 in Edinburgh, UK. Keynote reviews are given by both younger and senior scientists and are summarized in review papers. These review papers describe recent advances in a sub-discipline or topic and are regarded as tutorials in the future application of a particular method. These contributions are published as Special Issues of Surveys in Geophysics/Geophysical Surveys.

The 24th EMIW was held in Helsingør, Denmark, August 2018 (https://emiw2018.emiw. org/). The badge advertising the workshop is shown in Fig. 1. The event was a joint endeavour of the Nordic countries: Denmark, Finland, Iceland, Norway, and Sweden, and their associated territories: Greenland, the Faroe Islands, Svalbard, and the Alland Islands. They are located in the NW part of the Eurasian plate and in the NE part of the North-American plate and share location in the polar region. The workshop was attended by 302 participants from 38 countries. Some 345 abstracts were submitted to the following eight Workshop sessions:

Session 1 Instrumentation, sources, and data processing

Session 2 Theory, modelling, and inversion

Session 3 Exploration, monitoring, and hazards

Session 4 Tectonics, magmatism, and geodynamics

Session 5 Marine EM

Session 6 Rock and mineral resistivity, and anisotropy

Session 7 Global and planetary studies

Session 8 EM induction education and outreach

Maxim Smirnov

maxim.smirnov@1tu.se

Kiyoshi Baba

kbaba@eri.u-tokyo.ac.jp

1 Department of Civil, Environmental and Natural Resources Engineering, Luleå University of Technology, 97187 Luleå, Sweden

2 Earthquake Research Institute, The University of Tokyo, 1-1-1, Yayoi, Bunkyo-ku, Tokyo 113-0032, Japan 
Fig. 1 In the emblem for the 24th EMIW Workshop, an aurora (often observed in Nordic countries) is displayed over the Kronborg castle in Helsingør, where the Workshop was held

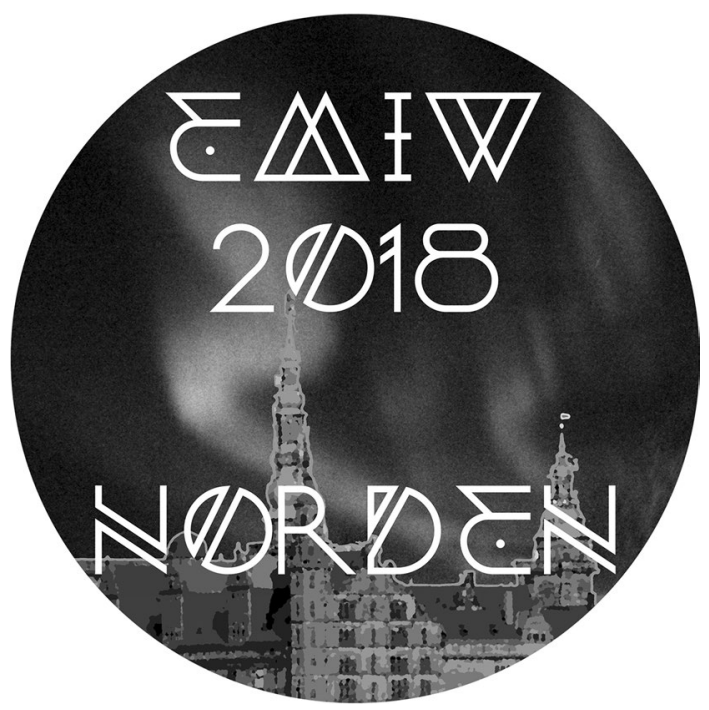

Five keynote reviews, focusing on sessions 1-4 and covering unique challenges in Earth sciences faced in the Nordic countries, were presented and three of them are published in this Special Issue.

Graham J. Hill (Institute of Geophysics, Czech Academy of Sciences, Prague, Czech Republic) has a long experience in collecting magnetotelluric data in Antarctica. In his review, he covers recent studies carried out in both polar regions, having many unresolved problems in the Earth sciences. The application of magnetotelluric methods in those regions has unique geographic and climatic challenges. He describes in detail logistical and instrumental problems and paves the way towards a successful methodology to carry out magnetotelluric observations in regions covered by snow. In particular, the very high contact resistance between electrodes and the surficial snow and ice cover (commonly $\mathrm{M} \Omega$ ) can interfere with the electric field measurements, unless taken care of by specifically designed instrumentation (high impedance buffer pre-amplifiers). The review covers several studies related to the development and application of EM methods in the polar regions. EM studies focusing on near surface hydrologic systems, glacial and ice sheet dynamics, as well as large-scale volcanic and tectonic problems are discussed. Hill (2020) thus provides an overview of the use of EM methods to investigate fundamental questions in solid Earth studies that have either been completed or are currently ongoing in both the Arctic and Antarctic.

Recent studies on electrical conductivity structure can treat three-dimensional (3D) heterogeneity as well as two-dimensional (2D) and one-dimensional (1D) heterogeneities by inversion analyses thanks to advances in computers and to the development of new numerical methods. Nowadays, the reliability of the obtained conductivity structure models is becoming a more important topic in the community, which is critical for a more quantitative interpretation of the models. Zhengyong Ren (School of Geosciences and Info-Physics, Central South University, Changsha, China) and Thomas Kalscheuer (Department of Earth Sciences, Uppsala University, Uppsala, Sweden) give a comprehensive review on uncertainty and resolution analysis of such inversion models. Ren and Kalscheuer (2020) first provide an exposition of the theory of linearized and nonlinear model analysis tools 
to estimate model uncertainty and resolution. They then show acceleration algorithms to quickly compute complete or partial model resolution and covariance matrices offered by linearized model analysis tools. Lastly, the main findings of published model analysis studies are summarized, with the positive expectation for further development of these studies as well as for optimal survey design and inversion grid design in the future.

Anna Kelbert (US Geological Survey, Denver, Colorado, USA) reviews recent developments in prediction hazards caused by geomagnetically induced currents (GICs) affecting man-made technological conductors that are grounded, in particular communication systems, pipelines, and, most significantly, electrical power grids. The strength of the GICs that flow through a transformer depends on many factors, including the spatio-temporal signature of the geomagnetic storm, the geometry and specifications of the power grid, and the 3D distribution of electrical conductivity in the Earth's subsurface. Kelbert (2020) provides a comprehensive review of GIC studies from around the world, with a focus on the effects that the Earth's electrical conductivity, specially its 3D structures, has on the induced currents in the electric power grids.

Finally, we, as Guest Editors, would like to express our gratitude to the Editor-in-Chief, Michael J. Rycroft, for his help with the editorial process, as well as A. Kuvshinov, K. Selway, A. Viljanen, P. Wannamaker and two anonymous referees, for their constructive and helpful reviews, and to the staff of Springer Nature for their diligence in preparing this Special Issue.

\section{References}

Hill GJ (2020) On the use of electromagnetics for earth imaging of the polar regions. Surv Geophys 41:141. https://doi.org/10.1007/s10712-019-09570-8

Kelbert A (2020) The role of global/regional earth conductivity models in natural geomagnetic hazard mitigation. Surv Geophys. https://doi.org/10.1007/s10712-019-09579-z

Ren Z, Kalscheuer T (2020) Uncertainty and resolution analysis of 2D and 3D inversion models computed from geophysical electromagnetic data. Surv Geophys 41:1-61. https://doi.org/10.1007/s10712-01909567-3

Publisher's Note Springer Nature remains neutral with regard to jurisdictional claims in published maps and institutional affiliations. 